IFAS Extension

\title{
Vida Saludable: Diabetes ${ }^{1}$
}

Linda B. Bobroff, Karla P. Shelnutt, and Paulina Wittkowsky ${ }^{2}$

\section{¿Qué es la diabetes?}

Diabetes es una condición en la cual se le hace difícil al cuerpo producir o usar la insulina. La insulina es una hormona que controla la cantidad de azúcar que hay en la sangre. Cuando una persona tiene diabetes, el cuerpo no produce insulina, produce muy poca insulina, o produce insulina que no trabaja correctamente. El resultado es la condición que conocemos comoc azúcar alta em la sangre.

\section{¿Qué sucede si tengo azúcar alta?}

Con el tiempo, el azúcar alta puede dañarle la vista y hasta causarle ceguera. También puede causarle daño a sus riñones, vasos sanguíneos y nervios. Personas con

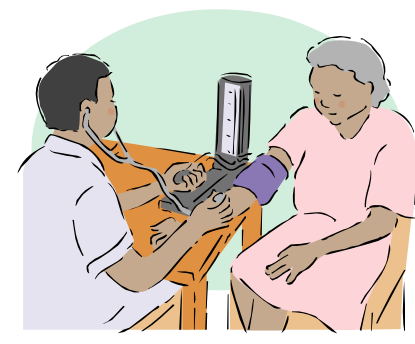
diabetes tienen mayor probabilidad de desarollar la tension arterial alta, que puede resultar en enfermedades cardíacas.

\section{¿Tengo riesgo de padecer de la diabetes?}

Algunos factores que pueden aumentar su riesgo de padecer de la diabetes son:
Herencia: Si alguno de sus padres, abuelos o hermanos ha padecido de la diabetes, usted tiene probabilidad de padecerla también.

Edad: Su cuerpo produce menos insulina con la edad.

* Origen racial: Si usted es de origen hispano, afro Americano, indio Americano o asiático Americano, usted tiene mayor riesgo de padecer de la diabetes.

Diabetes gestacional: Si usted padeció de la diabetes mientras que era embarazada, o su bebé pesó más de nueve libras al nacer, es más probable que usted padezca de la diabetes en el futuro.

\section{Obesidad: El}

sobrepeso aumenta su riesgo de padecer de la diabetes.

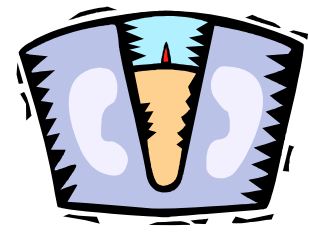

\section{¿Cuál es un peso saludable para mi?}

Las personas con mucha grasa acumulada, especialmente en el área de vientre, están en riesgo de desarrollar enfermedades como la diabetes. Usa esta tabla para identificar si estas sobre el nivel de un peso saludable.

1. The English version of this Spanish leaflet is Healthy Living: Diabetes (FCS8574). Este folleto, FCS8574span, pertenece a una serie del Departamento de Ciencias de la Familia, Juventud y Comunidad, Servicio de Extensión, Cooperativo de la Florida, Instituto de Alimentos. Fecha de publicación: marzo 2000. Revisado: diciembre 2006. Favor de visitar el EDIS Web site en el http://edis.ifas.ufl.edu.

2. Linda B. Bobroff, Ph.D., RD, LD/N., profesora; Karla P. Shelnutt, Ph.D., RD, ENAFS Coordinadora, Departamento de Ciencias de la Familia, Juventud y Comunidad, Servicio de Extensión Cooperativo de la Florida, Instituto de Alimentos y Ciencias Agrícolas, Universidad de la Florida. Diseño y traducción por Paulina Wittkowsky, MS, RD, anteriormente con la Universidad de la Florida, Gainesville, FL 32611. 
Para más información específica, vea las Guías Alimentarías para los

Estadounidenses de 2005.

\begin{tabular}{|c|c|c|}
\hline Altura & $\begin{array}{c}\text { Peso } \\
\text { Saludable } \\
\text { (lbs) }\end{array}$ & $\begin{array}{c}\text { Sobrepeso } \\
\text { (lbs) }\end{array}$ \\
\hline $5^{\prime}$ & 97 to 123 & 128 to 148 \\
\hline $5^{\prime} 2^{\prime \prime}$ & 104 to 131 & 136 to 158 \\
\hline $5^{\prime} 4^{\prime \prime}$ & 110 to 140 & 145 to 169 \\
\hline $5^{\prime} 6^{\prime \prime}$ & 118 to 148 & 155 to 179 \\
\hline $5^{\prime} 8^{\prime \prime}$ & 125 to 158 & 164 to 190 \\
\hline $5^{\prime} 10^{\prime \prime}$ & 132 to 167 & 174 to 202 \\
\hline $6^{\prime}$ & 140 to 177 & 184 to 213 \\
\hline $6^{\prime} 2^{\prime \prime}$ & 148 to 186 & 194 to 225 \\
\hline
\end{tabular}

\section{¿Cómo puedo saber si padezco de la diabetes?}

Millones de americanos padecen de la diabetes, iy la mitad de ellos no lo saben! Las personas que padecen de la diabetes pueden tener diferentes síntomas. Pueden tener todos, algunos o ninguno de las siguientes síntomas:

- Necesidad de orinar muy seguido (aún durante la noche)

- Sed o hambre constante

- Pérdida de peso sin explicación

- Piel reseca o comezón

- Infecciones de la piel

- Heridas o cortadas que tardan en sanar

- Hormigueo o pérdida de sensación en las manos o los pies

- Visión borrosa

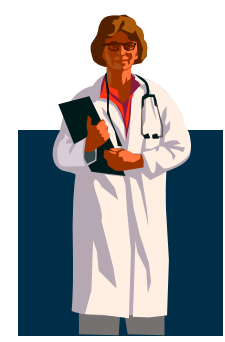

Un médico puede determinar si usted padece de la diabetes. Si usted tiene alguno de los síntomas antes mencionados, ivisite a su médico para

averiguarlo!Mientras más pronto te enteres de que tienes la diabetes, más pronto tomaras control de tu condición. Esto te hará sentir mejor y disminuarás los riesgos de complicaciones de salud.

\section{¿Existe una cura para la diabetes?}

En la mayoría de los casos de diabetes no hay cura. Perola diabetes puede ser controlada. Controlar la diabetes significa mantener normal su nivel de azúcar en la sangre. Usted puede hacerlo con una dieta adecuada y con actividad física. Algunas personas también necesitan inyecciones de insulina o medicamentos. Controlando su nivel de azúcar, usted reduce su riesgo de sufrir complicaciones de la salud.

\section{¿Como puedo controlar la diabetes?}

$\rightarrow$ Mantenga su nivel de azúcar en la sangre bajo control.

$\rightarrow$ Si está sobrepeso, pierda peso.

$\rightarrow$ Manténgase activo físicamente.

$\rightarrow$ Visite a un profesional de la salud regularmente para que le revise los ojos y la presión sanguínea.

$\rightarrow$ No fume.

$\rightarrow$ Siga una dieta saludable.

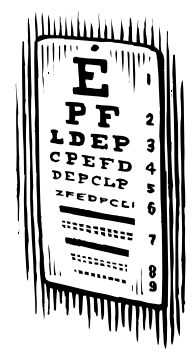

$\rightarrow$ Mantenga sus dientes limpios y vaya al dentista por lo menos dos veces al año.

$\rightarrow$ Visite a un profesional de la salud para que le revise los pies una vez al año. Revíselos usted mismo todos los días.

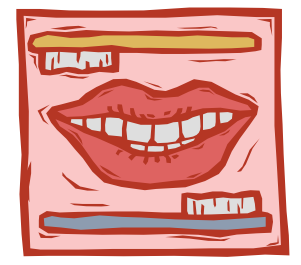




\section{¿Qué es una dieta saludable?}

Bajo en contenido de grasa, grasa saturada, y grasa trans.

Seleccione alimentos que contienen fibra, como granos integrales, frutas y vegetales.

Consuma menos azúcar, miel, dulces, refrescos, y té dulce.

Consuma menos productos con alto contenido de sal y sodio.

$>$ Antes de beber alcohol, pídale consejo a un profesional de la salud.

Si usted padece de la diabetes, una dietista (RD) puede diseñar una dieta que cumpla con sus necesidades.

\section{Para aprender más sobre la diabetes, o recursos disponibles relacionados al envejecimiento, contacte uno o más de estos recursos:}

\section{Asociación Americana de la Diabetes}

Llame al 1-800-DIABETES (1-800-342-2383) (disponible en ingles y español).

\section{Una dietista registrada $(\mathrm{RD})$}

Puede localizer a una dietista en su area llamando a la Asociación Americana de Dietética. Llame al 1-800-366-1655 (disponible en ingles y español). PáginaWeb: www.eatright.org

\section{Agente Local de Extensión de su Condado}

Busque “Cooperative Extension Service” en las páginas azules de su guía telefónica; en Florida puede encontrar la oficina de Extensión en su condado en la página Web de la Universidad de la Florida, Servicio de Extensión Cooperativa, Instituto de Alimentos y Ciencias Agrícolas: http://extension.ifas.ufl.edu

\section{La Sede Local de la Agencia para Asuntos del Envejecimiento}

Puede estar registrada en la sección de negocios de su guía telefónica; en Florida encuentre su sede local de la Agencia para Asuntos del Envejecimiento en la página Web de el Departamento de las Personas Mayores Estado de la Florida: http://elderaffairs.state.fl.us

USDA and USDHHS. Guías Alimentarias para los Estadounidenses 2005

Disponible en: http://www.usda.gov/cnpp 